\title{
Nuclear hormone receptors in parasitic helminths
}

\author{
Wenjie Wu ${ }^{1,2}$ and Philip T LoVerde ${ }^{3,4}$ \\ ${ }^{1}$ Department of Biochemistry, School of Medicine and Biomedical Science, State University of \\ New York, Buffalo, NY 14214, USA \\ 2Developmental Genomics Group, New York State Center of Excellence in Bioinformatics and \\ Life Sciences, 701 Ellicott Street, Buffalo, New York 14203, USA. \\ ${ }^{3}$ Departments of Biochemistry and Pathology, University of Texas Health Sciences Center, San \\ Antonio, Texas, 78229-3800, USA.
}

\section{Abstract}

Nuclear receptors (NRs) belong to a large protein superfamily that are important transcriptional modulators in metazoans. Parasitic helminths include parasitic worms from the Lophotrochozoa (Platyhelminths) and Ecdysozoa (Nematoda). NRs in parasitic helminths diverged into two different evolutionary lineages. NRs in parasitic Platyhelminths have orthologues in Deuterostomes, in arthropods or both with a feature of extensive gene loss and gene duplication within different gene groups. NRs in parasitic Nematoda follow the nematode evolutionary lineage with a feature of multiple duplication of SupNRs and gene loss.

\section{Keywords}

Ecdysozoa; Helminths; Lophotrochozoa; Nematoda; Nuclear receptors; Platyhelminths

\section{Introduction}

Nuclear receptors (NRs) belong to a large protein superfamily that are important transcriptional modulators in metazoans. They regulate homeostasis, differentiation, metamorphosis and reproduction (Gronemeyer \& Laudet 1995; Laudet \& Gronemeyer 2001). Since the first recognized NR (estrogen receptor, ER) in the 1950s (Jensen \& Jordan 2003) and the first isolated NR (human Glucocorticoid receptor, GR) in 1985 (Govindan et al. 1985), numerous NRs have been identified and isolated in various animals from Porifera (sponges) to mammals. NRs share a common tertiary structure, the typical NR contains a Nterminal A/B domain, a DNA binding domain (DBD), a hinge and a C-terminal ligand binding domain (LBD) (A/B-DBD-hinge-LBD). The A/B domain is highly variable and contains a ligand independent activation function (AF1). The DBD (also known as the $\mathrm{C}$ domain) is the most conserved region which contains two zinc finger motifs conferring sequence-specific DNA recognition to the regulatory region of the target gene. The conserved sequence of the first zinc finger (CI) which is Cys-X2-Cys-X13-Cys-X2-Cys

(C) 2010 Elsevier Ireland Ltd. All rights reserved.

${ }^{4}$ Corresponding author: Departments of Biochemistry and Pathology, University of Texas Health Sciences Center, 7703 Floyd Curl Dr., San Antonio, Texas, 78229-3800, USA. loverde@uthscsa.edu; phone: 1-210-567-73737; fax: 1-210-5676595.

Publisher's Disclaimer: This is a PDF file of an unedited manuscript that has been accepted for publication. As a service to our customers we are providing this early version of the manuscript. The manuscript will undergo copyediting, typesetting, and review of the resulting proof before it is published in its final citable form. Please note that during the production process errors may be discovered which could affect the content, and all legal disclaimers that apply to the journal pertain. 
contains a motif called the P-box (Lee et al. 1993; Luisi et al. 1991) which is responsible for binding to the target gene. The conserved sequence of the second zinc finger (CII) is described as Cys-X5-Cys-X9-Cys-X2-Cys with a motif called the D-box (Luisi et al. 1991) which is involved in dimerization. As more data has and continues to become available, the information indicates that the number of the amino acids in D-box is variable. Therefore, we suggest that the conserved sequence of the second zinc finger should be described as Cys$\mathbf{X x}$-Cys-X9-Cys-X2-Cys (Fig. 1). The hinge region (also called the D domain) is a poorly conserved sequence that functions as a flexible region between the DBD and LBD. The LBD contains the ligand binding pocket (LBP) in most NRs and is involved in transcriptional activation of target genes via binding of ligand and co-activators. Some NRs with no known ligand are called orphan receptors (Gronemeyer \& Laudet 1995; Laudet \& Gronemeyer 2001). Atypical NRs are found in some animals, NRs with a DBD but no LBD (NR0A) are found in arthropods and nematodes, members without a DBD but with a LBD (NR0B) are present in some vertebrates. Recently, NRs with two DBDs and a single LBD (2DBD-NRs) (A/B-DBDDBD-hinge-LBD) were identified in the trematode Schistosoma mansoni (Wu et al. 2006) and also in other invertebrates (Wu et al. 2007b) (Fig. 2). NRs are divided into six subfamilies (NR1-NR6) based on phylogenetic analysis of the conserved sequences with an extra subfamily NR0 (its members either contain only a DBD (NR0A) or only a LBD (NR0B)) (Committee 1999). The new group of NRs with two DBDs and a single LBD (Wu et al. 2007b) has yet to be included in this classification system (Committee 1999).

Helminths constitute a phylogenetic group including parasitic worms from two Phyla: Platyhelminths (flatworms) and Nematoda (roundworms). Parasitic Platyhelminths include trematodes (flukes), such as Schistosoma mansoni (blood fluke), Clonorchis sinensis (liver fluke), Paragonimus westermani (lung fluke) and Fasciolopsis buski (intestinal fluke), and Cestoda (tapeworms), such as Echinococcus granulosus (hydatid tape-worm) and Diphyllobothrium latum (fish or broad tapeworm). Nuclear receptors in Platyhelminths were first identified from S. mansoni (Escriva et al. 1997). Parasites in the Nematoda include some important human parasites such an Onchocerca volvulus, Brugia malayi, Ascaris lumbricoides and Trichinella spiralis. In recent years, the complete genome sequence from diverse animals has revealed the entire NR complement in organisms in Deuterostomia and Protostomia including the helminths Schistosoma mansoni and S. japonicum (Platyhelminths) and Brugia malayi and Meloidogyne incognita (Nemotoda).

\section{Nuclear receptors in parasitic Platyhelminths}

At present, NRs in parasitic Platyhelminths are only known in the trematodes Schistosoma mansoni and S. japonicum whose genomes have been sequenced (Berriman et al. 2009b; Liu et al. 2009).

A. NRs in S. mansoni-S. mansoni is a trematode which has evolved separate sexes and has a complex life cycle that involves mammalian and snail hosts. It is one of the causative agents of schistosomiasis. The complete NR complement in S. mansoni contains 21 members as reported by (Wu et al. 2006)) and was verified by S. mansoni genome sequence (Berriman et al. 2009a). Full length or partial cDNAs of all 21 NRs have been isolated (De Mendonca et al. 2002; de Mendonca et al. 2000; Freebern et al. 1999a; Freebern et al. 1999b; Hu et al. 2006b; Hu et al. 2006c; Lu et al. 2006b; Wu \& Loverde 2008; Wu et al. 2007a; Wu et al. 2006; Wu et al. 2007b; Wu et al. 2007c; Wu et al. 2008). S. mansoni NRs include six members in subfamily 1 (NR1), nine members in subfamily 2 (NR2), one member in subfamily 4 (NR4), two members in subfamily 5 (NR5) and three members with two DBDs and a single LBD (2DBD-NRs). No NRs were found in subfamily 3 (NR3) or subfamily 6 (NR6) (Wu et al. 2006). Phylogenetic analysis demonstrates that almost all of 
the $S$. mansoni NRs have orthologues either in Deuterostomes, in arthropods or both, except the three 2DBD-NRs and a divergent member NR1 member (SmNR1) (Figure 3a, 3b and Table 1). Among these 21 receptors, full length cDNA of 14 members have been isolated and studied.

SmTRa (AY395038) and SmTRß (AY395039) (NR1A): Two homologues of the vertebrate thyroid hormone receptors (THR, TR) were identified (Bertrand et al. 2004; Verjovski-Almeida et al. 2003; Wu et al. 2007a; Wu et al. 2006). Phylogenetic analysis demonstrates that these two copies are from a schistosoma-specific gene duplication (Wu et al. 2007a). S. mansoni was the first known protostome exhibiting TR homologues (Bertrand et al. 2004; Verjovski-Almeida et al. 2003; Wu et al. 2007a; Wu et al. 2006). Since then TR orthologues have also been found in S. japonicum and the free living platyhelminth, Schmidtea mediterranea, in the mollusc Lottia gigantea and the arthropod Daphnia pulex (Wu et al. 2007a). GST pull-down experiments show that both SmTR $\alpha$ and SmTR $\beta$ can form a heterodimer with one of the $S$. mansoni homologues of retinoid X receptor (SmRXR1). This suggests that non-chordate TRs are capable of forming a heterodimer with RXR like chordate TRs (Wu et al. 2007a). Electrophoretic mobility shift assays (EMSAs) show that SmTR $\alpha$ can bind, either as a monomer or as a homodimer, to a conserved DNA half-site AGGTCA, and to direct repeats of AGGTCA spaced with 0-5 nucleic acids (DR0DR5) and palindrome repeat of AGGTCA without spaced nucleic acids (Pal0), but SmTR $\beta$ shows weak binding to the same oligonucleotides as compared to SmTR $\alpha$ (Wu et al. 2007a). Although both SmTRs could form a heterodimer with SmRXR1, SmTR $\alpha /$ SmRXR1 or SmTR $\beta / S m R X R 1$ did not bind to the tested DNA elements, this may due to the flanking or spacing of nucleotides between the hormone receptor elements (HRE). With regards to whether SmTRs can bind to a T3/T4 ligand, sequence alignment of the LBD of SmTRs which is less conserved compared to vertebrate orthologues, suggest perhaps not. However, both SmTRs do exhibit a conserved consensus motif I and consensus motif II and a putative AF2 activation domain core (AF2-AD) (Wu et al. 2007a). Thus experimental studies are needed to answer the question of whether invertebrate TRs can bind to a cognate ligand.

SmE78 (AY395058) (NR1E): An orthologue of Drosophila ecdysone-induced protein 78 (E78) was identified in S. mansoni (Wu et al. 2006; Wu et al. 2008). Drosophila E78 plays a role directly related to ecdysone signaling. SmE78 is the first NR1E orthologue known outside of the Ecdysozoa. Quantitative real-time reverse-transcriptase polymerase chain reaction (qRT-PCR) shows that $S m E 78$ was expressed throughout schistosome development with the highest levels of expression in miracidia and the egg stages (Wu et al. 2008). Previous studies demonstrated that $S$. mansoni could synthesizes the steroid hormone ecdysone (Nirde et al. 1983) and that Ecdysterone was effective in stimulating host location activities in schistosome miracidia (Shiff \& Dossaji 1991). Whether SmE78 is involved in transduction of an ecdysone signal in S. mansoni remains to be demonstrated.

SmHR96 $\alpha$ (SmCAR) (AY663841, AY688258) (NR1J): SmHR96 $\alpha$ (SmCAR) is a homologue of Drosophila hormone receptor 96 (DHR96) which is a close member of vertebrate NRs in NR1I group (CAR/VDR/PXR) (Hu et al. 2006b; Wu et al. 2006). Yeast two-hybrid analysis, pull-down and co-immunoprecipitation assays demonstrated that SmCAR interacts with SmRXR1 but not SmRXR2 (Hu et al. 2006a). EMSAs demonstrate that SmCAR can bind to hsp2 ecdysone response element in a similar manner as Drosophila HR96, and to schistosome p14 female-specific gene upstream region (Hu et al. 2006b). mRNA of SmCAR is expressed in every stage of the S. mansoni life cycle with high expression levels in eggs and cercaria. SmCAR protein is found in subtegumental and parenchymal cells in both male and female worms. In addition, it is found in the ovaries, the eggs and the vitelline cells of mature female worms (Hu et al. 2006b). A second homologue of Drosophila NR96 (SmHR963) was identified in S. mansoni by cloning a partial cDNA 
that encodes a complete DBD (AY688259) (Wu et al. 2006) and by genome sequencing (Berriman et al. 2009a).

SmNR1 (AY395037, DQ439962) (NR1 divergent member): Phylogenetic analysis shows that SmNR1 clusters within NR subfamily 1 but outside of any known groups, thus SmNR1 is a divergent member (Wu et al. 2007c). Two alternative splice variants of SmNRI were identified, both variants encode the same protein sequence. SmNRI localizes on S. mansoni chromosome 1 as shown by fluorescent in situ hybridization (FISH) (Wu et al. 2007c). Yeast two-hybrid assay and glutathione S-transferase pull-down assay (GST-pull down) show that SmNR1 interacts with SmRXR1. EMSAs show that the heterodimer of SmNR1/ SmRXR1 can bind to DNA elements containing the half-site AGGTCA, a direct repeat of the half-site separated by 0-5 nucleotides (DR1-DR5), a palindrome repeat of the half-site without spaced nucleic acids (Pal0) (Wu et al. 2007c), and a p14-DR17 element (Fantappie et al. 2008b). Mutagenesis analysis shows that SmCBP1, a co-regulatory protein that was known to interact with SmFTZ-F1 (Bertin et al. 2006), can mediate the interactions with the LBD of SmRXR1 and SmNR1 (Fantappie et al. 2008a). Transient transfection in mammalian COS-7 cells shows that SmNR1/SmRXR1 can enhance the transcriptional activation of a DR2-dependent reporter gene (Wu et al. 2007c). qRT-PCR shows that mRNA of SmNRI was expressed throughout schistosome development with higher expression in eggs, sporocysts and 21-day-old worms (Wu et al. 2007c).

SmRXR1 (AF094759) and SmRXR2 (AF129816, AF158102) (NR2B): Two homologues of vertebrate RXR are present in S. mansoni (de Mendonca et al. 2000; Freebern et al. 1999a; Freebern et al. 1999b). Like SmTRs, these two copies of SmRXRs originated from a Schistosoma-specific gene duplication. RXRs play a central role in a variety of nuclear signaling pathways and modulate the activity of other nuclear receptors by forming heterodimers (Mangelsdorf et al. 1995). Yeast two-hybrid experiments and/or pull down experiments show that SmRXR1 can form a heterodimer with $\operatorname{SmTR} \alpha$ and SmTR $\beta$ (Wu et al. 2007a), SmHR96 $\alpha$ (SmCAR) (Hu et al. 2006a) and SmNR1 (Wu et al. 2007c). SmRXR1 alone can bind to cis-elements of the $S$. mansoni p14 gene (Fantappie et al. 2008b; Freebern et al. 1999b) and weakly on a half site of AGGTCA and its repeat of DR0-DR5 and Pal0 (Wu et al. 2007c). Smp14 is a female-specific gene whose expression is regulated by a stimulus from the male schistosome (LoVerde et al. 2004). Heterodimers of SmRXR1/ SmNR1 can bind to DNA elements containing the half-site AGGTCA, DR1-DR5 and Pal0 of this element (Wu et al. 2007c) and to the p14-DR17 element (Fantappie et al. 2008b). RTPCR shows that mRNA of SmRXR1 is constitutively expressed throughout development (Freebern et al. 1999b). The co-regulatory protein SmCBP1 is able to mediate interactions with SmRXR1 and SmNR1 (Fantappie et al. 2008a).

SmRXR2 was independently isolated by two laboratories (de Mendonca et al. 2000; Freebern et al. 1999b). Unlike SmRXR1, SmRXR2 could not form a heterodimer with SmTR $\alpha$ or SmTR $\beta$ (Wu et al. 2007a), SmHR96 $\alpha$ (SmCAR) (Hu et al. 2006a) or SmNR1 (Wu et al. 2007c). SmRXR2 does not bind to the consensus direct repeat response elements nor could the native SmRXR2 transactivate the transcription of a reporter gene in mammalian cells (de Mendonca et al. 2000). However, it can bind to cis-elements present in the S. mansoni p14 upstream region in a yeast reporter system (Fantappie et al. 2001). SmRXR1 and SmRXR2 fail to dimerize in a yeast two-hybrid system and in immunoprecipitation experiments (Fantappie et al. 2001). SmRXR2 mRNA is expressed at all life-cycle stages with higher levels in cercariae and miracidia, the free-living larval stages (de Mendonca et al. 2000; Freebern et al. 1999a). However, the protein expression is markedly different than that of the mRNA with the high levels in schistosomula but much lower levels in cercariae and miracidia (de Mendonca et al. 2000). 
SmTR4 (AY663842, AY688263) (NR2C): EMSAs show that the DBD of SmTR4 can bind to DR3 and DR4 that contain two AGGTCA half-sites spaced by three or four nucleotides. Yeast one-hybrid assay shows that the A/B, D and F domains each exhibit an autonomous transactivation activity (Hu et al. 2006c). SmTR2/4 mRNA is expressed in every tested developmental stage of $S$. mansoni with a higher level in cercaria. Western blot analysis identified two forms of SmTR2/4 protein with molecular sizes of about 230 and $245 \mathrm{kDa}$ in adult worms (Hu et al. 2006c).

SmNR4A4 (AY395064, AY688260) (NR4A): In humans and Drosophila NR4A members, there are four conserved phenylalanines in the LBD filling the entire volume of the ligand binding pocket (LBP) suggesting that NR4A receptors are true orphan receptors (Baker et al. 2003; Codina et al. 2004; Flaig et al. 2005). Three of these conserved phenylalanines are retained in SmNR4A, this result suggests that that the ancestral NR4 in the urbilateria was already an orphan receptor (Wu \& Loverde 2008). qRT-PCR shows mRNA of SmNR4A4 is regulated throughout development with different expression levels with a higher expression in the endoparasitic stages in both the snail and mammalian hosts and the highest expression is found in the daughter sporocysts and 35-day-old worms (Wu \& Loverde 2008).

SmFTZ-F1a (AY665680, AY688256) (NR5A): Phylogenetic analysis shows that SmFTZF1 $\alpha$ belongs to NR5A group (Lu et al. 2006b; Wu et al. 2006) while the previously isolated SmFTZ-F1 (AF158103) (De Mendonca et al. 2002) is an orthologue of Drosophila NHR39 (DHR39) which belongs to NR5B group (Lu et al. 2006b; Wu et al. 2006). EMSAs show that SmFTZ-F1 $\alpha$ can bind as a monomer to a response element FF1RE which is recognized by mammalian steroidogenic factor 1 (SF-1) (Lu et al. 2006a). Yeast one-hybrid experiments show that transactivation of reporter gene expression by SmFTZ-F1 $\alpha$ is A/B domain-dependent. Semi-quantitative RT-PCR shows that Smftz-fla is constitutively expressed throughout the schistosome life cycle with the highest level in the egg stage (Lu et al. 2006b). In situ RT-PCR on paraffin-embedded sections shows that expression of Smftz$f 1 \alpha$ is distributed throughout the parenchyma and the epithelial cells of the intestine.

Western blot analysis of a schistosome extract identified two proteins, one with a size (206 $\mathrm{kDa}$ ) predicted by the SmFTZ-F1 $\alpha$ cDNA sequence and a smaller component of $120 \mathrm{kDa}$ (Lu et al. 2006b).

SmFTZ-F1 (DHR39 orthologue) (NR5B): Phylogenetic analysis shows that SmFTZ-F1 (De Mendonca et al. 2002) is an orthologue of the Drosophila HR39 (DHR 39) (Lu et al. 2006b; Wu et al. 2006). Two alternative splice variants of SmFTZ-F1 have been identified (De Mendonca et al. 2002). EMSAs show that SmFTZ-F1 can bind to the response element for SF-1 and the DR0 of SFRE, but cannot bind DR-1 to DR-5 (De Mendonca et al. 2002). SmFTZ-F1 is able to transactivate transcription of a reporter gene in mammalian cell lines. Mammalian two-hybrid assay shows that the D, E and F domains of SmFtz-F1 are each capable of interacting with the LBD of SmRXR1, and suggests, for the first time, that a NR5 member can heterodimerize functionally with RXR (Bertin et al. 2005). Co-transfected CV-1 cells show that SmFTZ-F1 and SmRXR1 can transactivate transcription, but only SmFtz-F1 is physically bound to the promoter (De Mendonca et al. 2002). Functional studies showed that SmCBP1, a CREB-binding protein (CBP) in S. mansoni, could interact physically with SmFtz-F1 (Bertin et al. 2006). RT-PCR shows that Smftz-fl is expressed in all developmental stages with higher expression in the larval miracidia, sporocysts and cercariae, but the levels of protein expression are different from that of the mRNA with high levels in cercariae, schistosomula and male worms (De Mendonca et al. 2002).

NR with two DBDs and a single LBD (2DBD-NRs).: One of the most striking results in isolating NRs from $S$. mansoni is that a novel group of NRs that each contain two DBDs and a single LBD (2DBD-NRs) were identified (Fig. 2) (Wu et al. 2006; Wu et al. 2007b). 
Further analysis of available genome DNA databases shows that 2DBDNRs are present in other Protostomia such as free-living Plathelminths (Schmidtea mediterranea and Dugesia japonica), mollusks (Lottia gigantean) and arthropods (Daphnia pulex) (Wu et al. 2007b). Phylogenetic analysis of the 2DBD-NRs shows that the first DBD of 2DBD-NRs belongs to one monophyletic group and the second DBD belongs to a separate monophyletic group, this suggests that $2 D B D-N R s$ originated from a common ancestoral gene (Wu et al. 2007b). All 2DBD-NRs possess the same P-box sequence, CEACKK, in the first DBD which is not present in any other known NR (Wu et al. 2006; Wu et al. 2007b). This unique P-box of the first DBD of 2DBD-NRs may determine novel target DNA specificity.

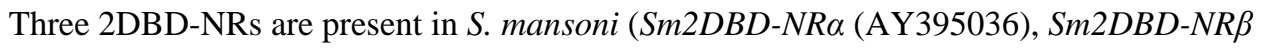
(AY688251) and Sm2DBD-NR (AY698061)). They are localized on different chromosomes as shown by FISH. This suggests that the $S m 2 D B D-N R s$ duplicated among different chromosomes (Wu et al. 2007b). Yeast two-hybrid experiments demonstrate that Sm2DBDNR $\alpha$ can interact as a homodimer but it does not interact with SmRXR1 or SmRXR2. GST pull-down experiments verify that the LBDs of Sm2DBD-NR $\alpha$ can form a homodimer in vitro (Wu et al. 2007b). The P-box motif located in the DBD is responsible for NRs acting on their target genes by recognizing and binding to specific DNA core motifs. Sm2DBDNR $\alpha$ interacting as a homodimer implies that four P-boxes may be involved in DNA binding and a novel mechanism of DNA binding is required to allow 2DBD-NR to bind to target DNA cis-elements. qRT-PCR shows that three of the Sm2DBDs are developmentally regulated and thus have a role in different development stages, Sm2DBD $\alpha$ was detected in sporocysts, cercariae, schistosomules, female and male worms, Sm2DBD $\beta$ was expressed at relatively high levels in eggs, sporocysts, cercariae and male stages, but Sm2DBD $\gamma$ was only detected in cercariae and 28-day worms (Wu et al. 2007b).

B. NRs in Schistosoma japonicum-S. japonicum is a sister species of S. mansoni whose genome was recently sequenced (Liu et al. 2009). Comparison of the NR complement of $S$. mansoni and S. japonicum shows that the two species share the same NR members except that $S$. japonicum has one or maybe two more 2DBD-NRs than S. mansoni (Table 1 and note at the bottom of the table). The authors of the S. japonicum sequence (Liu et al. 2009) claim to have found an orthologue of the glucocorticoid receptor (GR), the ecdysonelike receptor (EcR) and the estrogen receptor-related receptor (ERR), that were missing in S. mansoni. We reanalyzed the DNA sequences of $S$. japonicum and our results show that $S$. japonicum 'GR' (Sjp_0026760, Sjp_0002350) actually is a homologue of S. mansoni RXR1 (SmRXR1, AF094759), S. japonicum 'EcR' (FSE001-P00030-D02 (SJFCE5380)) (see supplementary table 22 of (Liu et al. 2009)) is an orthologue of SmHR96a/SmCAR (AY663841, AY688258), and the S. japonicum estrogen-related receptor beta like" (ERR) (FSE001-P00011-A06, supplementary table 22 of (Liu et al. 2009)) is not a nuclear receptor. Thus the suggestion, based on the 'discovery' of GR and EcR in S. japonicum, that the schistosome can utilize host hormones as ligands to regulate parasite gene expression and schistosomes can interact with ecdysone in the same way as in the Ecdysozoa (Liu et al. 2009) needs confirmation and at this point is incorrect.

C. NRs in tapeworms-No NR data is available for tapeworms (Cestoda). However, experiments suggest that there is endogenous production of testosterone which is thought to be important for the development of the larva of Taenia crassiceps. Cysticerci of $T$. crassiceps can produce testosterone from steroid precursors that may be important for parasite growth and development (Romano et al. 2003). The genomes of Echinococcus multilocularis and Taenia solium are currently being sequenced (Aguilar-Diaz et al. 2006). That information will open the door for studies on cestode NRs. 


\section{Nuclear receptors in parasitic nematodes}

Nematodes belong to the Ecdysozoa, a group characterized by the presence of a thick outer covering called the cuticle which is both tough and flexible. In nematodes, the cuticle is shed as it molts from one stage to the next, usually four times before reaching the adult stage, during its life cycle. Molting which is best characterized in insects (Aguinaldo et al. 1997) is regulated by ecdysone and involves NRs. It is likely that the role of EcR and RXR/USP in parasitic nematode molting will soon be resolved, as the genomes of two parasitic nematodes, Brugia malayi and Meloidogyne incognita, have been sequenced and reveal the complete NR complement in these two species. Functioanl studies on the nematode EcR and RXR/USP are just beginning to appear (Tzertzinis et al. 2010; Shea et al. 2010; Graham et al. 2010). In addition, cDNAs of other NRs have been isolated and studied in several parasitic nematodes such as in Filaria (Brugia. malayi, B. pahangi, Onchocerca volvulus and Dirofilaria immitis) in Rhabditida (Strongyloides stercoralis) and in hookworms (Ancylostoma spp.,Ancylostoma ceylanicum, A. caninum and Necator americanus).

\section{A. NRs in Filaria}

a. NRs in Brugia malayi: B. malayi is a human parasitic nematode transmitted by mosquitoes. It is one of the causative agents of lymphatic filariasis (elephantiasis) in humans (Hoerauf 2008). Twenty-seven NRs have been identified in the B. malayi genome (Ghedin et al. 2007), ten of them are orthologues of Drosophila/vertebrates NRs including an orthologue of EcR and RXR (which are not present in Caenorhabditis elegans), and an E75, E78, ROR, DHR96, TLL, fax-1, Coup-TF1 and a NR4A (Table 1). An orthologue of OvNHR-1 (a divergent nematode member in NR subfamily 1 (Wu et al. 2007c; Yates et al. 1995)) is also present in B. malayi.

Bm-nhr-11 (EU003172) (NR1D): Bm-nhr-11 was shown to be an orthologue of Drosophila E75 (NR1D), RT-PCR shows that mRNA of Bm-nhr-11 expresses at a low level in adult males but at a higher level in females and L4 larvae (Crossgrove et al. 2008).

Bma-EcR (EF362469, EF362470) (NR1H): Two isoforms of Bma-EcR were identified (Tzertzinis et al. 2010). Northern blot analyses showed that Bma-EcR expressed in adult males, females, L1, L2 and L3 larval stages. Both isoforms of Bma-EcR were able to bind a canonical ecdysone response element (EcRE) when partnered with USP (orthologue of RXR in Drosophila). The most prominent feature in Bma-EcR is the absence of the conserved helix 12 residues. Transcriptional activation assay showed that Bma-EcR can dimerize with Bma-RXR and that the LBD of Bma-EcR was capable of transducing an ecdysteroid signal in mammalian cells (Tzertzinis et al. 2010).

Bma-RXR (EF362471) (NR2B): The protein of Bma-RXR was shown to be expressed in adult males, females and L1 larvae (Tzertzinis et al. 2010). The expression pattern of BmaRXR differs from that of the dog filarial RXR, Di-RXR-1, as Di-RXR-1 is not expressed in female worms. Bma-RXR can dimerize with Bma-EcR and the LBD of Bma-EcR was capable of transducing an ecdysteroid signal in a mammalian cell system (Shea et al. 2004; Tzertzinis et al. 2010).

b. NRs in Brugia pahangi: $B$. pahangi is a sister species of $B$. malayi which infects the lymph vessels of domestic cats and wild animals. Partial cDNAs of two B. pahangi NRs have been isolated (Moore \& Devaney 1999).

Bp-nhr-1 (AF091046): RT-PCR shows that mRNA of Bp-nhr-1 is expressed at very low levels in larvae, adult and microfilariae (Moore \& Devaney 1999). 
Bp-nhr-2 (AF091044): RT-PCR shows that mRNA of Bp-nhr-2 is expressed in early stages after infection, adult worms and microfilariae, and is up-regulated just before the molt between the L3 and L4 stages. No expression was tested during the molt between L4 and the adult stage. Western blot analysis shows that the protein is expressed in microfilariae and adult parasites (Moore \& Devaney 1999).

c. NRs in Onchocerca volvulus: $O$. volvulus is a human parasite transmitted by black flies that causes Onchocerciasis (River Blindness). Two NRs have been isolated from $O$. volvulus.

OvNHR-1 (OVU19360) (NR1 divergent member): Phylogenetic analysis shows that OvNHR-1 (Yates et al. 1995) is a divergent member in NR subfamily 1 (Wu et al. 2007c) and one of its orthologues is present in B. malayi (Ghedin et al. 2007). mRNA expression of OvNHR- 1 was shown to be developmentally regulated with a high level of expression during early embryogenesis. OvNR-1 was demonstrated to be antigenic in $O$. volvulus infected individuals (Unnasch et al. 1988; Yates et al. 1995).

OvNHR-2 (AF170551) (NR1E): Phylogenetic analysis shows that OvNR-2 is a close member of Drosophila E78 (NR1E) (Unnasch et al. 1999). OvNR-2 mRNA expression was shown to be tightly regulated in the adult female stage, appearing only in intrauterine microfilariae (Unnasch et al. 1999).

Interestingly, Onchocerca has been shown to concentrate retinol. In this regard retinoic acid binding proteins were identified (Sani et al. 1985). As retinoids act through retinoic acid receptors (RAR) in vertebrates, the identification of a RAR from the Brugia genome would facilitate studies to understand the role of these molecules in Onchocerca biology specifically and nematode biology in general.

OvNHR-4 (Ov-RXR) (EF362472) (NR2B): A cDNA of OvNHR-4 was isolated and remains to be characterized (Tzertzinis et al. 2010).

d. NRs in Dirofilaria immitis: D. immitis (dog heartworm) is transmitted by mosquitoes and is the causative agent of dog heartworm disease.

Di-nhr-6 (EU003171) (NR1D): Di-nhr-6 was shown to be an orthologue of Bmnhr-11 and E75 (NR1D). qRT-PCR demonstrated that mRNA expression of Di-nhr-6 is at a high level in L3 larvae and female worms, but at very low levels in microfilaria (Crossgrove et al. 2008).

Di-nhr-7 (AF367206, AF367207, AF367208) (NR1E/G): cDNAs of three isoforms of Di$n h r-7$ were isolated (Crossgrove et al. 2002). Phylogenetic analysis shows that Di-nhr-7 is an orthologue of the DHR E78 (NR1E/G), EMSAs show that Di-NHR-7 can bind to Rev-erb response elements Rev-DR2 as a dimmer and Rev-DR4 as a monomer. Northern blot analysis shows that Di-nhr-7 expression is female-specific (Crossgrove et al. 2002).

DiEcR (GQ149497, GQ149498, GQ149499) (NR1H): cDNA of three isoforms of an orthologue of Drosophila EcR (NR1H) were isolated (Shea et al. 2010). Pull-down experiments showed that DiEcR could form a heterodimer with the Di-RXR-1 and mosquito Aedes aegypti USP. EMSA showed that DiEcR required USP as a partner to bind hsp27 EcRE (ATTGGACAAGTGCATTGAACCCTTGTCTCT). DiEcR could activate transcription of a reporter gene in a ligand-dependent manner when utilizing a 9-cis retinoic acid-activated mouse RXR as a partner in mammalian cells (Shea et al. 2010). 
Di-RXR-1 (AF438229, AF438230) (NR2B): Di-RXR-1 was the first RXR/USP orthologue (NR2B) characterized in nematodes (Shea et al. 2004). Di-RXR-1 mRNA was detected in adult females but not in males. It could dimerize with Drosophila EcR and transcription was activated in the presence of 20-hydroxyecdysone using Drosophila Schneider S2 cells in an ecdysone-dependent manner (Shea et al. 2004).

B. NRs in Meloidogyne incognita-M. incognita (root-knot nematode) is a plant nematode parasite which attacks the roots of plants. Ninety-two NRs are predicted in the $M$. incognita genome with six orthologues of Drosophila/vertebrate NRs including two homologues of ROR (NR1F), two homologues of DHR96 (NR1I/J/K), a TLL (NR2E) and a fax-1 (NR2E) member (Table 1). Forty-one members are found to be orthologues of nematode SupNRs, 14 of them are shown to be orthologues of $C$. elegans and/or B. malayi (Abad et al. 2008). No further data for M. incognita NRs are currently available.

\section{NR in parasitic nematode threadworm and hookworms}

a. Orthologues of $C$. elegans DAF12: C. elegans larvae can undergo arrest and form dauer larvae. The infective larvae from nematodes (eg, L3 larvae of Strongyloides, Ancylostoma and Necator) also undergo arrest and are strikingly similar to dauer larvae (Hotez et al. 1993). The nuclear receptor DAF-12 binds the steroid hormone dafrachonic acid to regulate dauer formation in C. elegans. Orthologues of C. elegans DAF-12 have been identified in the human parasitic threadworm Strongyloides stercoralis, and parasitic hookworms Ancylostoma duodenale (human hookworm), A. ceylanicum (panspecific hookworm), A. caninum (dog hook worm) and Necator americanus (human hookworm) (Strube et al. 2007; Wang et al. 2009). The full length cDNAs of the orthologue of DAF-12 were isolated in $S$. stercoralis (SsDAF-12, AF145048, BG225375) and A. caninum (AcDAF-12, BQ125240) (Wang et al. 2009), partial cDNAs of that were identified in A. ceylanicum (AceDAF-12, CB276910) and Necator americanus (NaDAF-12) (Strube et al. 2007; Wang et al. 2009). In vivo and in vitro experiments show that the ligand of C. elegans DAF-12, $\Delta^{4}$ dafachronic acid ( $\Delta 4$-DA) and $\Delta^{7}$ dafachronic acid ( $\Delta 7$-DA) (Motola et al. 2006), can activate AcDAF-12 and SsDAF-12 (Wang et al. 2009). Interestingly, dafrachonic acid treatment of Strongyloides L3 larvae resulted in a reduction in the infective L3 population. This coupled with the crystal structure of the SsDAF-12 LBD complexed with a coactivator LXXLL peptide and $\triangle 4$-DA or $\triangle 7$-DA showing that the architecture SsDAF-12 LBD is similar to other members of the NR superfamily, identifies a target for novel drug therapy (Wang et al. 2009).

b. Haemonchus contortus EcR (HcEcR) (GU250809) (NR1H): cDNA of an orthologue of Drosophila EcR (NR1H) was isolated in H. contortus, a parasitic hookworm of ruminants (Graham et al. 2010) (Graham et al. 2010). The D-E-F domains of HcEcR could not form a heterodimer with D-E-F domains of Drosophila USP and did not bind to $\left[3^{\mathrm{H}}\right]$ ponasterone A in a insect cell system (Graham et al. 2010). The demonstration of the ability to heterodimerize awaits the identification of an appropriate partner.

\section{Evolution of NRs in helminths}

Helminths form a polyphyletic group containing two different lineages in the Protostomia: Platyhelminths belong to the lophotrochozoan clade and Nematoda belong to the ecdysozoan clade. Schistosome genome projects were the first to describe genomes from the lophotrochozoan clade (Berriman et al. 2009a; Liu et al. 2009). Phylogenetic analysis of the NR complement in both $S$. mansoni and $S$. japonicum shows that most of NRs in parasitic Platyhelminths have orthologues either in Deuterostomes, in arthropods or both. For example, 17 of 21 S. mansoni NRs have homologues in Drosophila and/or chordates (Wu et al. 2006). Interestingly, one divergent Schistosoma member, SmNR1 (Wu et al. 2007c), and 
its $S$. japonicum orthologue (SjNR1) evolved specifically in subfamily 1 . This member was not found in other Protostomia (including other Platyhelminths, unpublished data), which suggests that SmNR1 and SjNR1 originated from a common NR1 ancestor after the Platyhelminths diverged from other lophotrochozoans or after trematodes diverged from other Platyhelminths (no data currently available from other trematodes). Comparison of the NR complement in S. mansoni and S. japonicum with that of insects (Bonneton et al. 2008; Cheng et al. 2008; Tan \& Palli 2008; Velarde et al. 2006) shows that many of the schistosome NRs appeared by gene duplication within gene groups while almost no gene duplication occurred within gene groups in insects. Thus though schistosomes and insects have a similar number of NRs, fewer NR gene groups are present in schistosome NRs (Fig. $3 \mathrm{a}$ and $3 \mathrm{~b}$ ). This suggests that gene lost and duplication which is more frequent in schistosomes than insects may have been an adaptation to the parasitic life style. This conjecture awaits further data.

NRs regulate transcription by recognizing and binding to the DNA element of their target genes. The functional relationship between RXR/USP with other NRs was described as the 1-2-3-4-5 rule (Shulemovich et al. 1995; Umesono et al. 1991; Wilson et al. 1992). For example, vertebrate RXR/RAR heterodimer can bind to DR1, DR2 and DR5 but not to DR3 or DR4, RXR/VDR heterodimer can bind to DR3 but not to DR1, DR2, DR4 or DR5 (Andersson et al. 1992; Desvergne 1994; Predki et al. 1994; Schrader \& Carlberg 1994; Shaffer \& Gewirth 2004). Drosophila USP/EcR heterodimer can bind to DR0-DR5 (Wilson et al. 1992). In schistosomes, SmNR1/SmRXR1 heterodimer can bind to DR0-DR5 (Wu et al. 2007c) similar to the Drosophila USP/EcR heterodimer (Wilson et al. 1992). Vertebrate TR homodimer can bind to DR4 but not DR1, DR2, DR3 or DR5 (Andersson et al. 1992; Naar et al. 1991; Sap et al. 1989; Umesono et al. 1991), while SmTR homodimer can bind to DR0-DR5 (Wu et al. 2007a). These results suggest that the RXR/NR heterodimer and TR homodimer acquired the ability to bind to conserved half-site repeats before the split of the Platyhelminths and Arthopods, but has not subsequently evolved a specificity for strict spacing between half-sites as that in vertebrates (Wu et al. 2007a; Wu et al. 2007c).

Unlike NRs in ecdysozoan Arthopods (most data are from the Insecta), free living nematodes Caenorhabditis elegans and C. briggsae contain more than 250-270 NRs, most of them originated from a unique burst of HNF4 duplications (supplementary NRs, SupNRs) (Robinson-Rechavi et al. 2005). Caenorhabditis sp. only exhibit 12-13 conserved NRs (Bertrand et al. 2004; Maglich et al. 2001; Sluder \& Maina 2001; Sluder et al. 1999; Stein et al. 2003). Among the 92 predicted NRs in the plant parasitic nematode M. incognita, only six NRs share homologues with Drosophila/vertebrates. Forty-one members are homologues of nematode SupNRs (Abad et al. 2008). Of 27 B. malayi NRs, less than half are orthologues of Drosophila/vertebrates NRs (Ghedin et al. 2007), some B. malayi NRs are homologues of nematode SupNRs of C. elegans and/or M. incognita (Abad et al. 2008; Ghedin et al. 2007). These data suggest that the expansion of SupNRs occurred before the split of free living Caenorhabditis, animal parasitic nematode Brugia and plant parasitic nematode Meloidogyne and then multiple duplication events occurred independently in different nematode lineages (Abad et al. 2008; Bird et al. 2009).

The above data demonstrates that the NRs in parasitic helminths diverged into two different evolutionary lineages. NRs in parasitic Platyhelminths (data only available for schistosome) have orthologues either in Deuterostomes, in arthropods or both with a feature of extensive gene loss and gene duplication within different gene groups. NRs in parasitic nematodes follow the nematode evolutionary lineage with a feature of multiple duplication of SupNRs and gene loss. 
With the increase in the genomic information from helminths available to the scientific community, we can expect a concomitant increase in the number of studies that elucidate the role of nuclear receptors in host-parasite interactions. For example, the identification of DAF-12 as a NR that governs the development of the L3 infective pathway and offers a novel therapeutic target (Wang et al. 2009).

\section{Acknowledgments}

This research was supported by a National Institute of Health grant AI46762.

\section{References}

Abad P, Gouzy J, Aury JM, Castagnone-Sereno P, Danchin EG, Deleury E, Perfus-Barbeoch L, Anthouard V, Artiguenave F, Blok VC, Caillaud MC, Coutinho PM, Dasilva C, De Luca F, Deau F, Esquibet M, Flutre T, Goldstone JV, Hamamouch N, Hewezi T, Jaillon O, Jubin C, Leonetti P, Magliano M, Maier TR, Markov GV, McVeigh P, Pesole G, Poulain J, Robinson-Rechavi M, Sallet E, Segurens B, Steinbach D, Tytgat T, Ugarte E, van Ghelder C, Veronico P, Baum TJ, Blaxter M, Bleve-Zacheo T, Davis EL, Ewbank JJ, Favery B, Grenier E, Henrissat B, Jones JT, Laudet V, Maule AG, Quesneville H, Rosso MN, Schiex T, Smant G, Weissenbach J, Wincker P. Genome sequence of the metazoan plant-parasitic nematode Meloidogyne incognita. Nat Biotechnol 2008;26:909-15. [PubMed: 18660804]

Aguilar-Diaz H, Bobes RJ, Carrero JC, Camacho-Carranza R, Cervantes C, Cevallos MA, Davila G, Rodriguez-Dorantes M, Escobedo G, Fernandez JL, Fragoso G, Gaytan P, Garciarubio A, Gonzalez VM, Gonzalez L, Jose MV, Jimenez L, Laclette JP, Landa A, Larralde C, Morales-Montor J, Morett E, Ostoa-Saloma P, Sciutto E, Santamaria RI, Soberon X, de la Torre P, Valdes V, Yanez J. The genome project of Taenia solium. Parasitol Int 2006;55(Suppl):S127-30. [PubMed: 16337432]

Aguinaldo AM, Turbeville JM, Linford LS, Rivera MC, Garey JR, Raff RA, Lake JA. Evidence for a clade of nematodes, arthropods and other moulting animals. Nature 1997;387:489-93. [PubMed: 9168109]

Andersson ML, Nordstrom K, Demczuk S, Harbers M, Vennstrom B. Thyroid hormone alters the DNA binding properties of chicken thyroid hormone receptors alpha and beta. Nucleic Acids Res 1992;20:4803-10. [PubMed: 1408794]

Baker KD, Shewchuk LM, Kozlova T, Makishima M, Hassell A, Wisely B, Caravella JA, Lambert MH, Reinking JL, Krause H, Thummel CS, Willson TM, Mangelsdorf DJ. The Drosophila orphan nuclear receptor DHR38 mediates an atypical ecdysteroid signaling pathway. Cell 2003;113:73142. [PubMed: 12809604]

Berriman M, Haas B, LoVerde P, Wilson R, Dillon G, Cerqueira G, Mashiyama S, Al-Lazikani B, Andrade L, Ashton P, Aslett M, Bartholomeu D, Blandin G, Caffrey C, Coghlan A, Coulson R, Day T, Delcher A, DeMarco R, Djikeng A, Eyre T, Gamble J, Ghedin E, Gu Y, Hertz-Fowler C, Hirai H, Hirai Y, Houston R, Ivens A, Johnston D, Lacerda D, Macedo C, McVeigh P, Ning Z, Oliveira G, Overington J, Parkhill J, Pertea M, Pierce R, Protasio A, Quail M, Rajandream M, Rogers J, Sajid M, Salzberg S, Stanke M, Tivey A, White O, Williams D, Wortman J, Wu W, Zamanian M, Zerlotini A, Fraser-Liggett C, Barrell B, El-Sayed N. The genome of the blood fluke Schistosoma mansoni. Nature 2009a;460:352-8. [PubMed: 19606141]

Berriman M, Haas BJ, Loverde PT, Wilson RA, Dillon GP, Cerqueira GC, Mashiyama ST, AlLazikani B, Andrade LF, Ashton PD, Aslett MA, Bartholomeu DC, Blandin G, Caffrey CR, Coghlan A, Coulson R, Day TA, Delcher A, Demarco R, Djikeng A, Eyre T, Gamble JA, Ghedin E, Gu Y, Hertz-Fowler C, Hirai H, Hirai Y, Houston R, Ivens A, Johnston DA, Lacerda D, Macedo CD, McVeigh P, Ning Z, Oliveira G, Overington JP, Parkhill J, Pertea M, Pierce RJ, Protasio AV, Quail MA, Rajandream MA, Rogers J, Sajid M, Salzberg SL, Stanke M, Tivey AR, White O, Williams DL, Wortman J, Wu W, Zamanian M, Zerlotini A, Fraser-Liggett CM, Barrell BG, ElSayed NM. The genome of the blood fluke Schistosoma mansoni. Nature 2009b;460:352-8. [PubMed: 19606141] 
Bertin B, Caby S, Oger F, Sasorith S, Wurtz JM, Pierce RJ. The monomeric orphan nuclear receptor Schistosoma mansoni Ftz-F1 dimerizes specifically and functionally with the schistosome RXR homologue, SmRXR1. Biochem Biophys Res Commun 2005;327:1072-82. [PubMed: 15652506]

Bertin B, Oger F, Cornette J, Caby S, Noel C, Capron M, Fantappie MR, Rumjanek FD, Pierce RJ. Schistosoma mansoni $\mathrm{CBP} / \mathrm{p} 300$ has a conserved domain structure and interacts functionally with the nuclear receptor SmFtz-F1. Mol Biochem Parasitol 2006;146:180-91. [PubMed: 16427147]

Bertrand S, Brunet FG, Escriva H, Parmentier G, Laudet V, Robinson-Rechavi M. Evolutionary genomics of nuclear receptors: from twenty-five ancestral genes to derived endocrine systems. Mol Biol Evol 2004;21:1923-37. [PubMed: 15229292]

Bird DM, Williamson VM, Abad P, McCarter J, Danchin EG, Castagnone-Sereno P, Opperman CH. The genomes of root-knot nematodes. Annu Rev Phytopathol 2009;47:333-51. [PubMed: 19400640]

Bonneton F, Chaumot A, Laudet V. Annotation of Tribolium nuclear receptors reveals an increase in evolutionary rate of a network controlling the ecdysone cascade. Insect Biochem Mol Biol 2008;38:416-29. [PubMed: 18342247]

Cheng D, Xia Q, Duan J, Wei L, Huang C, Li Z, Wang G, Xiang Z. Nuclear receptors in Bombyx mori: insights into genomic structure and developmental expression. Insect Biochem Mol Biol 2008;38:1130-7. [PubMed: 18992339]

Codina A, Benoit G, Gooch JT, Neuhaus D, Perlmann T, Schwabe JW. Identification of a novel coregulator interaction surface on the ligand binding domain of Nurr1 using NMR footprinting. J Biol Chem 2004;279:53338-45. [PubMed: 15456745]

Committee NRN. A unified nomenclature system for the nuclear receptor superfamily. Cell 1999;97:161-163. [PubMed: 10219237]

Crossgrove K, Laudet V, Maina CV. Dirofilaria immitis encodes Di-nhr-7, a putative orthologue of the Drosophila ecdysone-regulated E78 gene. Mol Biochem Parasitol 2002;119:169-77. [PubMed: 11814569]

Crossgrove K, Maina CV, Robinson-Rechavi M, Lochner MC. Orthologues of the Drosophila melanogaster E75 molting control gene in the filarial parasites Brugia malayi and Dirofilaria immitis. Mol Biochem Parasitol 2008;157:92-7. [PubMed: 17942167]

De Mendonca RL, Bouton D, Bertin B, Escriva H, Noel C, Vanacker JM, Cornette J, Laudet V, Pierce RJ. A functionally conserved member of the FTZ-F1 nuclear receptor family from Schistosoma mansoni. Eur J Biochem 2002;269:5700-11. [PubMed: 12423370]

de Mendonca RL, Escriva H, Bouton D, Zelus D, Vanacker JM, Bonnelye E, Cornette J, Pierce RJ, Laudet V. Structural and functional divergence of a nuclear receptor of the RXR family from the trematode parasite Schistosoma mansoni. Eur J Biochem 2000;267:3208-19. [PubMed: 10824105]

Desvergne B. How do thyroid hormone receptors bind to structurally diverse response elements? Mol Cell Endocrinol 1994;100:125-31. [PubMed: 8056146]

Escriva H, Safi R, Hanni C, Langlois MC, Saumitou-Laprade P, Stehelin D, Capron A, Pierce R, Laudet V. Ligand binding was acquired during evolution of nuclear receptors. Proc Natl Acad Sci U S A 1997;94:6803-8. [PubMed: 9192646]

Fantappie MR, Bastos de Oliveira FM, de Moraes Maciel R, Rumjanek FD, Wu W, Loverde PT. Cloning of SmNCoA-62, a novel nuclear receptor co-activator from Schistosoma mansoni: assembly of a complex with a SmRXR1/SmNR1 heterodimer, SmGCN5 and SmCBP1. Int J Parasitol 2008a;38:1133-47. [PubMed: 18359485]

Fantappie MR, Freebern WJ, Osman A, LaDuca J, Niles EG, LoVerde PT. Evaluation of Schistosoma mansoni retinoid X receptor (SmRXR1 and SmRXR2) activity and tissue distribution. Mol Biochem Parasitol 2001;115:87-99. [PubMed: 11377743]

Fantappie MR, Furtado DR, Rumjanek FD, Loverde PT. A unique nuclear receptor direct repeat 17 (DR17) is present within the upstream region of Schistosoma mansoni female-specific p14 gene. Biochem Biophys Res Commun 2008b;371:689-93. [PubMed: 18455507]

Flaig R, Greschik H, Peluso-Iltis C, Moras D. Structural basis for the cell-specific activities of the NGFI-B and the Nurr1 ligand-binding domain. J Biol Chem 2005;280:19250-8. [PubMed: 15716272] 
Freebern WJ, Niles EG, LoVerde PT. RXR-2, a member of the retinoid x receptor family in Schistosoma mansoni. Gene 1999a;233:33-8. [PubMed: 10375618]

Freebern WJ, Osman A, Niles EG, Christen L, LoVerde PT. Identification of a cDNA encoding a retinoid X receptor homologue from Schistosoma mansoni. Evidence for a role in female-specific gene expression. J Biol Chem 1999b;274:4577-85. [PubMed: 9988692]

Ghedin E, Wang S, Spiro D, Caler E, Zhao Q, Crabtree J, Allen JE, Delcher AL, Guiliano DB, Miranda-Saavedra D, Angiuoli SV, Creasy T, Amedeo P, Haas B, El-Sayed NM, Wortman JR, Feldblyum T, Tallon L, Schatz M, Shumway M, Koo H, Salzberg SL, Schobel S, Pertea M, Pop M, White O, Barton GJ, Carlow CK, Crawford MJ, Daub J, Dimmic MW, Estes CF, Foster JM, Ganatra M, Gregory WF, Johnson NM, Jin J, Komuniecki R, Korf I, Kumar S, Laney S, Li BW, Li W, Lindblom TH, Lustigman S, Ma D, Maina CV, Martin DM, McCarter JP, McReynolds L, Mitreva M, Nutman TB, Parkinson J, Peregrin-Alvarez JM, Poole C, Ren Q, Saunders L, Sluder AE, Smith K, Stanke M, Unnasch TR, Ware J, Wei AD, Weil G, Williams DJ, Zhang Y, Williams SA, Fraser-Liggett C, Slatko B, Blaxter ML, Scott AL. Draft genome of the filarial nematode parasite Brugia malayi. Science 2007;317:1756-60. [PubMed: 17885136]

Govindan MV, Devic M, Green S, Gronemeyer H, Chambon P. Cloning of the human glucocorticoid receptor cDNA. Nucleic Acids Res 1985;13:8293-304. [PubMed: 2417195]

Graham LD, Kotze AC, Fernley RT, Hill RJ. An ortholog of the ecdysone receptor protein (EcR) from the parasitic nematode Haemonchus contortus. Mol Biochem Parasitol 2010;171:104-107. [PubMed: 20226216]

Gronemeyer H, Laudet V. Transcription factors 3: nuclear receptors. Protein Profile 1995;2:1173-308. [PubMed: 8681033]

Hoerauf A. Filariasis: new drugs and new opportunities for lymphatic filariasis and onchocerciasis. Curr Opin Infect Dis 2008;21:673-81. [PubMed: 18978537]

Hotez P, Hawdon J, Schad GA. Hookworm larval infectivity, arrest and amphiparatenesis: the Caenorhabditis elegans Daf-c paradigm. Parasitol Today 1993;9:23-6. [PubMed: 15463660]

Hu R, Niles EG, LoVerde PT. DNA binding and transactivation properties of the Schistosoma mansoni constitutive androstane receptor homologue. Mol Biochem Parasitol 2006a;150:174-85. [PubMed: 16962182]

$\mathrm{Hu}$ R, Wu W, Niles EG, Loverde PT. Isolation and characterization of Schistosoma mansoni constitutive androstane receptor. Mol Biochem Parasitol 2006b;148:31-43. [PubMed: 16603257]

Hu R, Wu W, Niles EG, LoVerde PT. SmTR2/4, a Schistosoma mansoni homologue of TR2/TR4 orphan nuclear receptor. Int J Parasitol 2006c;36:1113-22. [PubMed: 16839558]

Huelsenbeck JP, Ronquist F. MRBAYES: Bayesian inference of phylogenetic trees. Bioinformatics 2001;17:754-5. [PubMed: 11524383]

Jensen EV, Jordan VC. The estrogen receptor: a model for molecular medicine. Clin Cancer Res 2003;9:1980-9. [PubMed: 12796359]

Laudet, V.; Gronemeyer, H. The Nuclear Receptor Factsbook. Academic Press; 2001.

Lee MS, Kliewer SA, Provencal J, Wright PE, Evans RM. Structure of the retinoid X receptor alpha DNA binding domain: a helix required for homodimeric DNA binding. Science 1993;260:111721. [PubMed: 8388124]

Liu F, Zhou Y, Wang ZQ, Lu G, Zheng H, Brindley PJ, McManus DP, Blair D, Zhang QH, Zhong Y, Wang S, Han ZG, Chen Z. The Schistosoma japonicum genome reveals features of host-parasite interplay. Nature 2009;460:345-51. [PubMed: 19606140]

LoVerde PT, Niles EG, Osman A, Wu WJ. Schistosoma mansoni male-female interactions. Canadian Journal of Zoology-Revue Canadienne De Zoologie 2004;82:357-374.

Lu C, Niles EG, LoVerde PT. Characterization of the DNA-binding properties and the transactivation activity of Schistosoma mansoni nuclear receptor fushi tarazu-factor 1alpha (SmFTZ-F1alpha). Mol Biochem Parasitol 2006a;150:72-82. [PubMed: 16890303]

Lu C, Wu W, Niles EG, LoVerde PT. Identification and characterization of a novel fushi tarazu factor 1 (FTZ-F1) nuclear receptor in Schistosoma mansoni. Mol Biochem Parasitol 2006b;150:25-36. [PubMed: 16870276] 
Luisi BF, Xu WX, Otwinowski Z, Freedman LP, Yamamoto KR, Sigler PB. Crystallographic analysis of the interaction of the glucocorticoid receptor with DNA. Nature 1991;352:497-505. [PubMed: 1865905]

Maglich JM, Sluder A, Guan X, Shi Y, McKee DD, Carrick K, Kamdar K, Willson TM, Moore JT. Comparison of complete nuclear receptor sets from the human, Caenorhabditis elegans and Drosophila genomes. Genome Biol 2001;2:RESEARCH0029. [PubMed: 11532213]

Mangelsdorf DJ, Thummel C, Beato M, Herrlich P, Schutz G, Umesono K, Blumberg B, Kastner P, Mark M, Chambon P, Evans RM. The nuclear receptor superfamily: the second decade. Cell 1995;83:835-9. [PubMed: 8521507]

Moore J, Devaney E. Cloning and characterization of two nuclear receptors from the filarial nematode Brugia pahangi. Biochem J 1999;344(Pt 1):245-52. [PubMed: 10548557]

Motola DL, Cummins CL, Rottiers V, Sharma KK, Li T, Li Y, Suino-Powell K, Xu HE, Auchus RJ, Antebi A, Mangelsdorf DJ. Identification of ligands for DAF-12 that govern dauer formation and reproduction in C. elegans. Cell 2006;124:1209-23. [PubMed: 16529801]

Naar AM, Boutin JM, Lipkin SM, Yu VC, Holloway JM, Glass CK, Rosenfeld MG. The orientation and spacing of core DNA-binding motifs dictate selective transcriptional responses to three nuclear receptors. Cell 1991;65:1267-79. [PubMed: 1648451]

Nirde P, Torpier G, De Reggi ML, Capron A. Ecdysone and 20 hydroxyecdysone: new hormones for the human parasite schistosoma mansoni. FEBS Lett 1983;151:223-7. [PubMed: 6832354]

Predki PF, Zamble D, Sarkar B, Giguere V. Ordered binding of retinoic acid and retinoid-X receptors to asymmetric response elements involves determinants adjacent to the DNA-binding domain. Mol Endocrinol 1994;8:31-9. [PubMed: 8152429]

Robinson-Rechavi M, Maina CV, Gissendanner CR, Laudet V, Sluder A. Explosive lineage-specific expansion of the orphan nuclear receptor HNF4 in nematodes. J Mol Evol 2005;60:577-86. [PubMed: 15983867]

Romano MC, Valdez RA, Cartas AL, Gomez Y, Larralde C. Steroid hormone production by parasites: the case of Taenia crassiceps and Taenia solium cysticerci. J Steroid Biochem Mol Biol 2003;85:221-5. [PubMed: 12943707]

Sani BP, Vaid A, Comley JC, Montgomery JA. Novel retinoid-binding proteins from filarial parasites. Biochem J 1985;232:577-83. [PubMed: 3004410]

Sap J, Munoz A, Schmitt J, Stunnenberg H, Vennstrom B. Repression of transcription mediated at a thyroid hormone response element by the v-erb-A oncogene product. Nature 1989;340:242-4. [PubMed: 2569164]

Schrader M, Carlberg C. Thyroid hormone and retinoic acid receptors form heterodimers with retinoid $\mathrm{X}$ receptors on direct repeats, palindromes, and inverted palindromes. DNA Cell Biol 1994;13:333-41. [PubMed: 8011161]

Shaffer PL, Gewirth DT. Vitamin D receptor-DNA interactions. Vitam Horm 2004;68:257-73. [PubMed: 15193458]

Shea C, Hough D, Xiao J, Tzertzinis G, Maina CV. An rxr/usp homolog from the parasitic nematode, Dirofilaria immitis. Gene 2004;324:171-82. [PubMed: 14693382]

Shea C, Richer J, Tzertzinis G, Maina CV. An EcR homolog from the filarial parasite, Dirofilaria immitis requires a ligand-activated partner for transactivation. Mol Biochem Parasitol 2010;171:55-63. [PubMed: 20170689]

Shiff CJ, Dossaji SF. Ecdysteroids as regulators of host and parasite interactions: a study of interrelationships between Schistosoma mansoni and the host snail, Biomphalaria glabrata. Trop Med Parasitol 1991;42:11-6. [PubMed: 2052849]

Shulemovich K, Dimaculangan DD, Katz D, Lazar MA. DNA bending by thyroid hormone receptor: influence of half-site spacing and RXR. Nucleic Acids Res 1995;23:811-8. [PubMed: 7708497]

Sluder AE, Maina CV. Nuclear receptors in nematodes: themes and variations. Trends Genet 2001;17:206-13. [PubMed: 11275326]

Sluder AE, Mathews SW, Hough D, Yin VP, Maina CV. The nuclear receptor superfamily has undergone extensive proliferation and diversification in nematodes. Genome Res 1999;9:103-20. [PubMed: 10022975] 
Stein LD, Bao Z, Blasiar D, Blumenthal T, Brent MR, Chen N, Chinwalla A, Clarke L, Clee C, Coghlan A, Coulson A, D'Eustachio P, Fitch DH, Fulton LA, Fulton RE, Griffiths-Jones S, Harris TW, Hillier LW, Kamath R, Kuwabara PE, Mardis ER, Marra MA, Miner TL, Minx P, Mullikin JC, Plumb RW, Rogers J, Schein JE, Sohrmann M, Spieth J, Stajich JE, Wei C, Willey D, Wilson RK, Durbin R, Waterston RH. The genome sequence of Caenorhabditis briggsae: a platform for comparative genomics. PLoS Biol 2003;1:E45. [PubMed: 14624247]

Strube C, von Samson-Himmelstjerna G, Schnieder T. Genetic regulation of arrested development in nematodes: are age-1 and daf-gene orthologs present in Dictyocaulus viviparus? Parasitol Res 2007;101:1111-5. [PubMed: 17558520]

Tan A, Palli SR. Identification and characterization of nuclear receptors from the red flour beetle, Tribolium castaneum. Insect Biochem Mol Biol 2008;38:430-9. [PubMed: 18342248]

Tzertzinis G, Egana AL, Palli SR, Robinson-Rechavi M, Gissendanner CR, Liu C, Unnasch TR, Maina CV. Molecular evidence for a functional ecdysone signaling system in Brugia malayi. PLoS Negl Trop Dis 2010;4:e625. [PubMed: 20231890]

Umesono K, Murakami KK, Thompson CC, Evans RM. Direct repeats as selective response elements for the thyroid hormone, retinoic acid, and vitamin D3 receptors. Cell 1991;65:1255-66. [PubMed: 1648450]

Unnasch TR, Bradley J, Beauchamp J, Tuan R, Kennedy MW. Characterization of a putative nuclear receptor from Onchocerca volvulus. Mol Biochem Parasitol 1999;104:259-69. [PubMed: 10593180]

Unnasch TR, Gallin MY, Soboslay PT, Erttmann KD, Greene BM. Isolation and characterization of expression cDNA clones encoding antigens of Onchocerca volvulus infective larvae. J Clin Invest 1988;82:262-9. [PubMed: 2455736]

Velarde RA, Robinson GE, Fahrbach SE. Nuclear receptors of the honey bee: annotation and expression in the adult brain. Insect Mol Biol 2006;15:583-95. [PubMed: 17069634]

Verjovski-Almeida S, DeMarco R, Martins EA, Guimaraes PE, Ojopi EP, Paquola AC, Piazza JP, Nishiyama MY Jr. Kitajima JP, Adamson RE, Ashton PD, Bonaldo MF, Coulson PS, Dillon GP, Farias LP, Gregorio SP, Ho PL, Leite RA, Malaquias LC, Marques RC, Miyasato PA, Nascimento AL, Ohlweiler FP, Reis EM, Ribeiro MA, Sa RG, Stukart GC, Soares MB, Gargioni C, Kawano T, Rodrigues V, Madeira AM, Wilson RA, Menck CF, Setubal JC, Leite LC, Dias-Neto E. Transcriptome analysis of the acoelomate human parasite Schistosoma mansoni. Nat Genet 2003;35:148-57. [PubMed: 12973350]

Wang Z, Zhou XE, Motola DL, Gao X, Suino-Powell K, Conneely A, Ogata C, Sharma KK, Auchus RJ, Lok JB, Hawdon JM, Kliewer SA, Xu HE, Mangelsdorf DJ. Identification of the nuclear receptor DAF-12 as a therapeutic target in parasitic nematodes. Proc Natl Acad Sci U S A 2009;106:9138-43. [PubMed: 19497877]

Wilson TE, Paulsen RE, Padgett KA, Milbrandt J. Participation of non-zinc finger residues in DNA binding by two nuclear orphan receptors. Science 1992;256:107-10. [PubMed: 1314418]

Wu W, Loverde PT. Schistosoma mansoni: identification of SmNR4A, a member of nuclear receptor subfamily 4. Exp Parasitol 2008;120:208-13. [PubMed: 18682251]

$\mathrm{Wu}$ W, Niles E, LoVerde P. Thyroid hormone receptor orthologues from invertebrate species with emphasis on Schistosoma mansoni. BMC Evol Biol 2007a;7:150. [PubMed: 17727708]

Wu W, Niles EG, El-Sayed N, Berriman M, LoVerde PT. Schistosoma mansoni (Platyhelminthes, Trematoda) nuclear receptors: sixteen new members and a novel subfamily. Gene 2006;366:30315. [PubMed: 16406405]

Wu W, Niles EG, Hirai H, LoVerde PT. Evolution of a novel subfamily of nuclear receptors with members that each contain two DNA binding domains. BMC Evol Biol 2007b;7:27. [PubMed: 17319953]

Wu W, Niles EG, Hirai H, LoVerde PT. Identification and characterization of a nuclear receptor subfamily I member in the Platyhelminth Schistosoma mansoni (SmNR1). FEBS J 2007c; 274:390-405. [PubMed: 17173548]

Wu W, Tak EY, LoVerde PT. Schistosoma mansoni: SmE78, a nuclear receptor orthologue of Drosophila ecdysone-induced protein 78. Exp Parasitol 2008;119:313-8. [PubMed: 18430421] 
Yates RA, Tuan RS, Shepley KJ, Unnasch TR. Characterization of genes encoding members of the nuclear hormone receptor superfamily from Onchocerca volvulus. Mol Biochem Parasitol 1995;70:19-31. [PubMed: 7637701] 


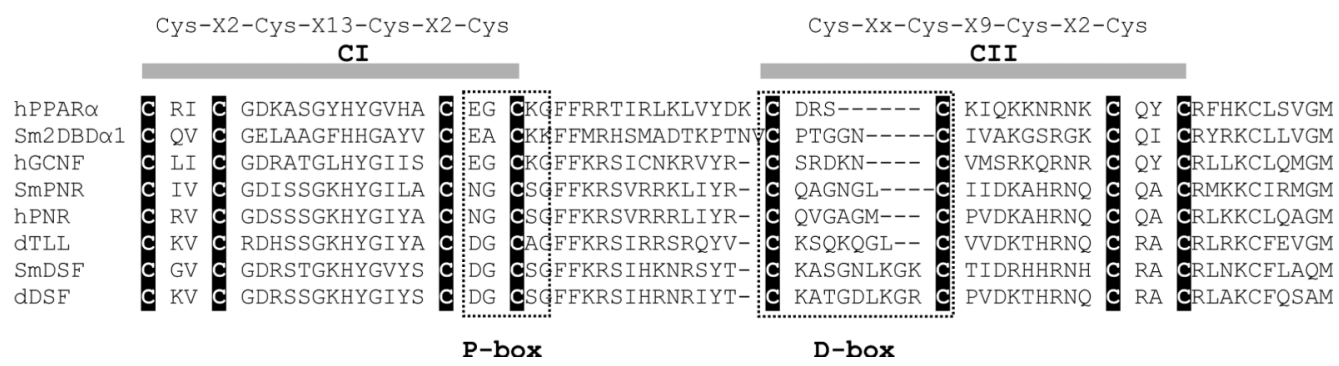

Figure 1. Sequence alignment of the DNA binding domain of selected NRs showing the two zinc fingers and the conserved motifs

$\mathrm{CI}$ : the first zinc finger with a conserved motif sequence of Cys-X2-Cys-X13-Cys-X2-Cys, CII: the second zinc finger with a conserved motif sequence of Cys-Xx-Cys-X9-Cys-X2Cys. Cys: cysteine residue, $\mathrm{X}$ followed with a number indicates the number of amino acids between the Cys. Xx indicates the variation in the number of amino acids in the D-box (herein shows 3-9 amino acids). Sm2DBD $\alpha 1$ : The first DBD of Sm2DBDNR $\alpha$. The dotted boxes indicate the amino acid sequences of $\mathrm{P}$ and $\mathrm{D}$ boxes. 


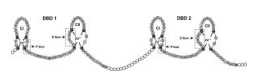

Figure 2. The DNA binding domain (DBD) of 2DBD-NR

Circles represent amino acids. Black circles with $\mathrm{C}$ represent the cysteines that contact $\mathrm{Zn}^{++}$. Circles without a letter represent the amino acids outside the DBD. The dotted boxes indicate the $\mathrm{P}$ and $\mathrm{D}$ boxes. The 2-DBD domain shown in the figure is that of Sm2DBD$\mathrm{NR} \alpha$. 


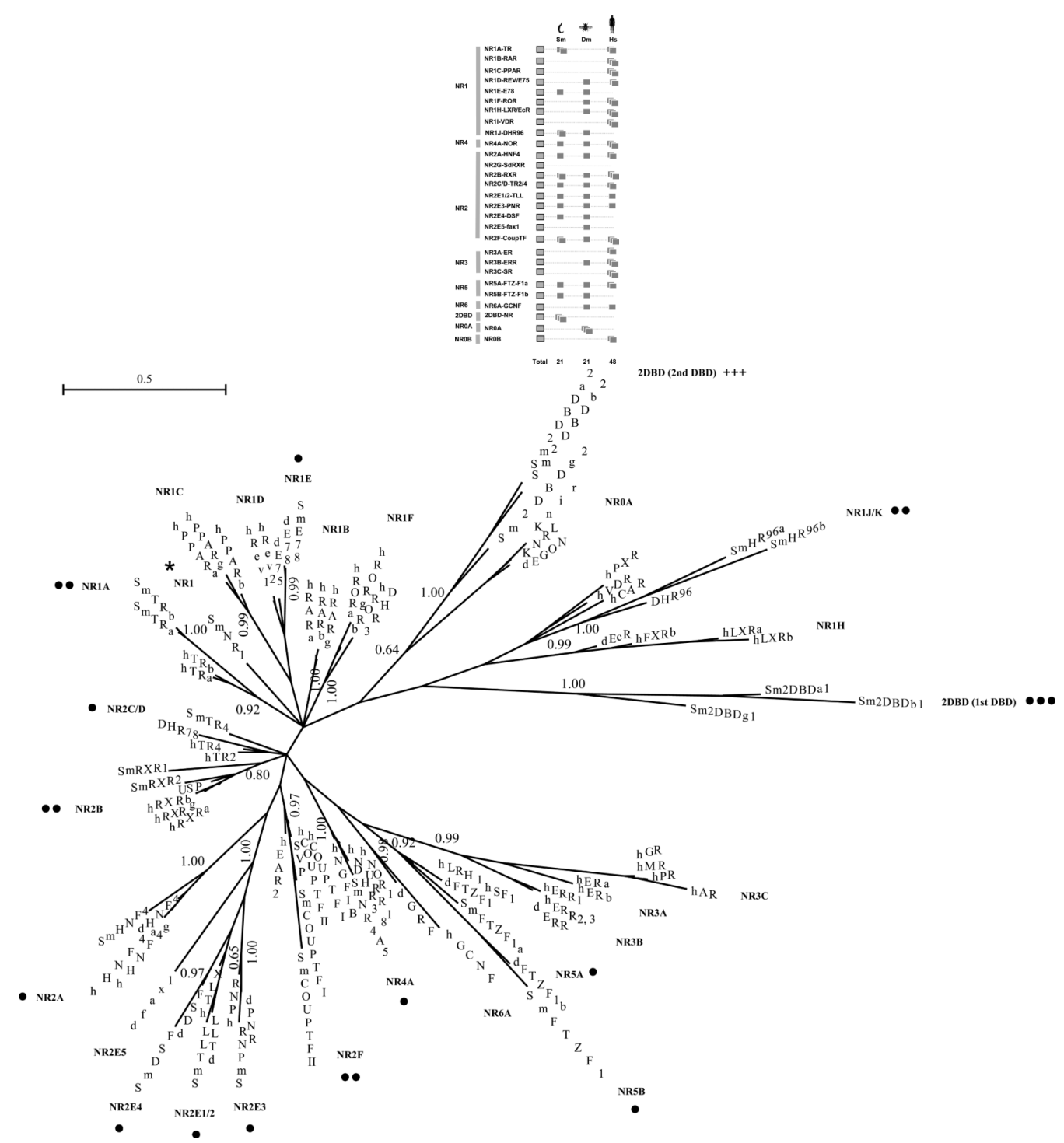

Figure 3. A schematic figure and an unrooted phylogenetic tree representing $S$. mansoni nuclear receptors

a Schematic figure summarizes the identification of the NRs in S. mansoni, and provides a comparison with NRs in Drosophila melanogaster and Homo sapiens. Each square box indicates a NR member. Dm indicates Drosophila melanogaster, Hm indicates Homo sapiens and Sm indicates S. mansoni. b. Unrooted Bayesian tree analysis of NRs in $S$. mansoni. The phylogenetic tree was constructed from peptide sequences of the DBD, peptide sequences were aligned with ClustalW (http://www.cf.ac.uk/biosi/research/biosoft/Downloads/clustalw.html). The data set was carried out under the proportion of invariable sites and gamma-distributed rate heterogeneity among sites with a mixed amino acid replacement model using MrBAYES v3.1.1

(Huelsenbeck \& Ronquist 2001). The trees were started randomly; four simultaneous Markov chains were run for 5 million generations with the tree being sampled every 100 generations. Bayesian posterior probabilities (PPs) were calculated using a Markov chain Monte Carlo (MCMC) sampling approach implemented in MrBayes v3.1.1, with the burn-in values set at 7,500 and shown at the branch nodes. Two human NR0B members (without DBD) were not analyzed. DHR or d before the NR name indicate Drosophila melanogaster 
NRs, h indicates human NRs and Sm indicates $S$. mansoni NRs. The dots indicate the number of $S$. mansoni NRs found in different NR groups, a star shows a divergent $\mathrm{S}$. mansoni NR member and +++ indicate the second DBD of 2DBD-NRs. 


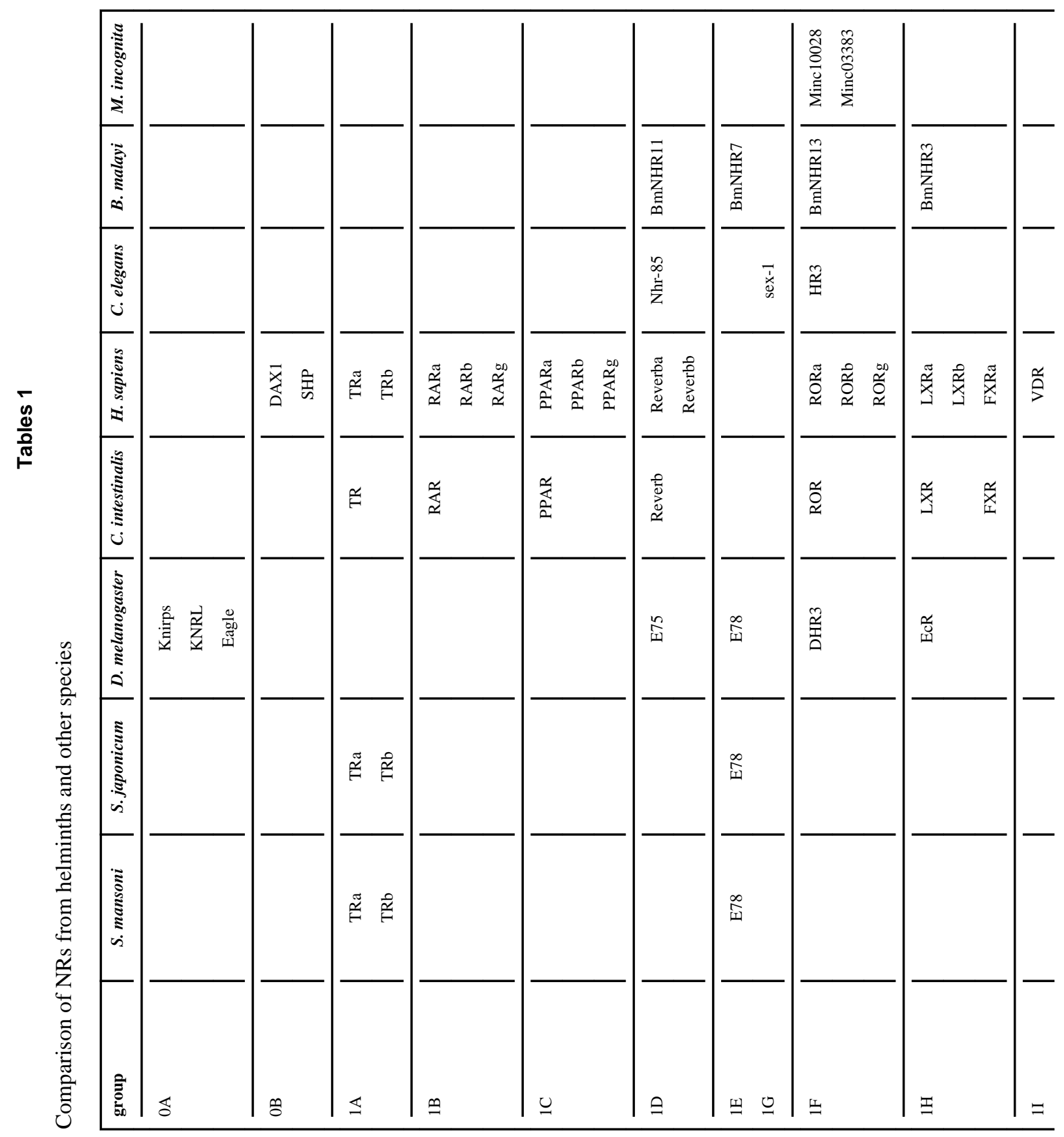

Mol Cell Endocrinol. Author manuscript; available in PMC 2012 March 1. 


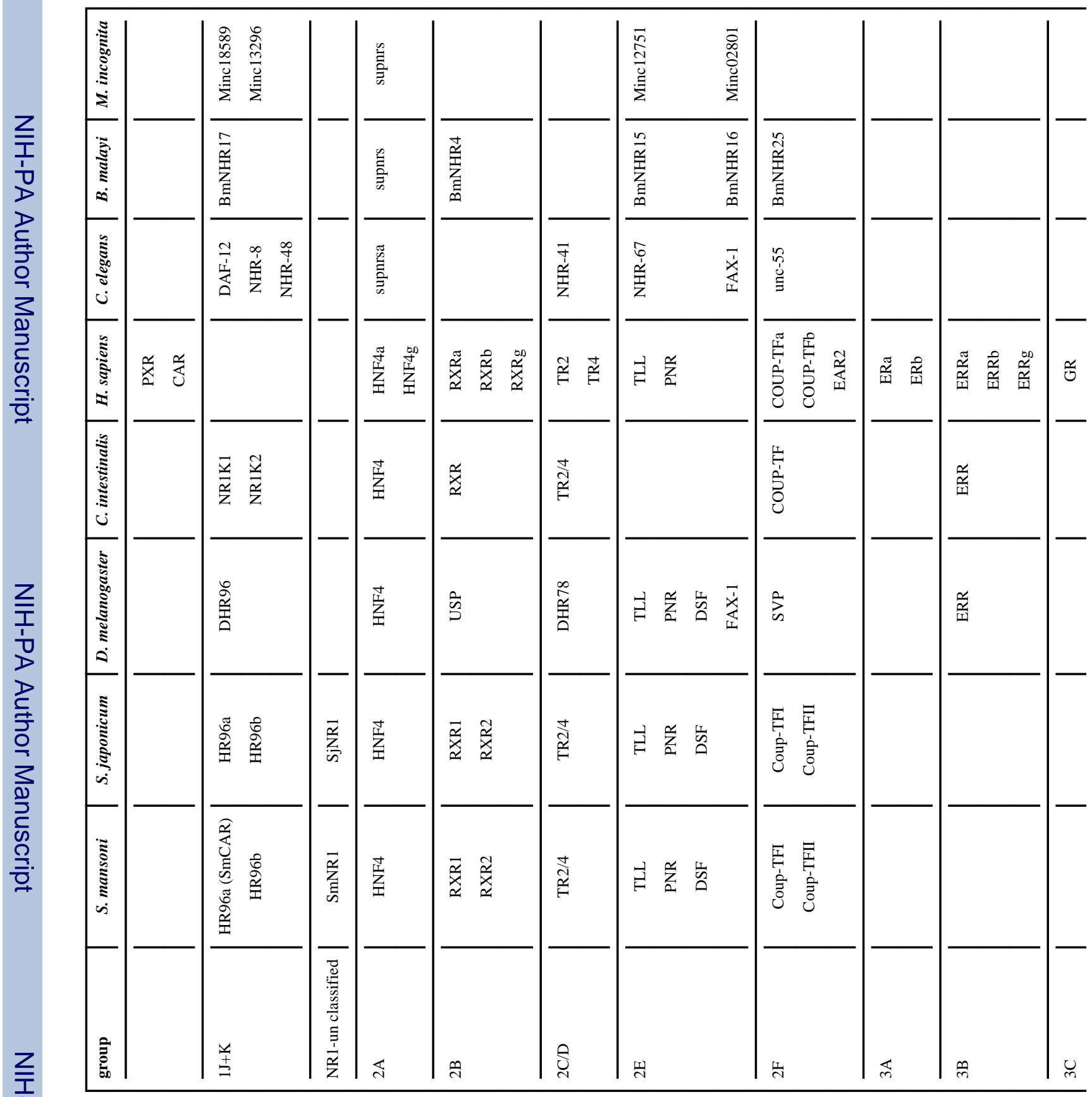




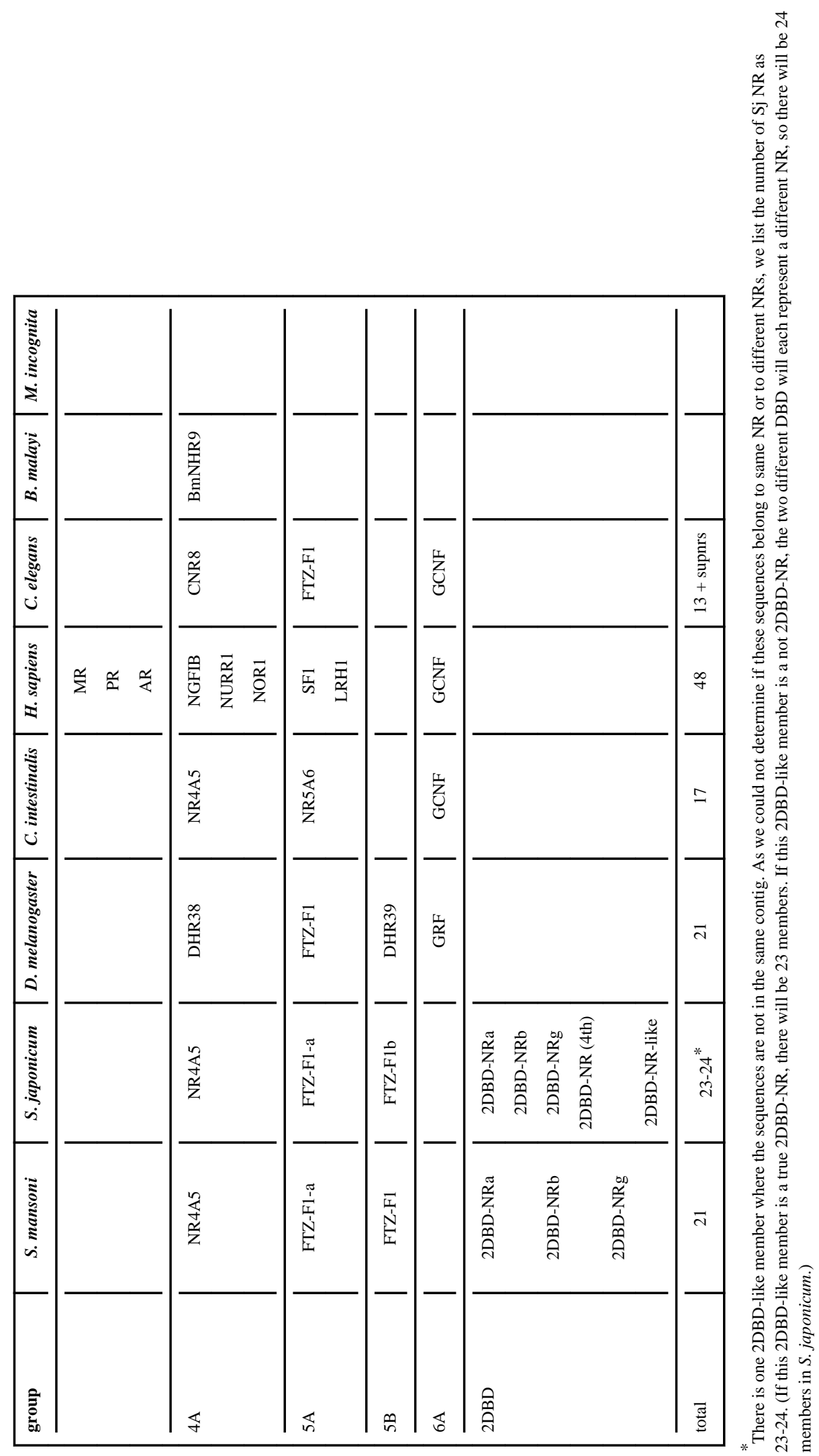

Mol Cell Endocrinol. Author manuscript; available in PMC 2012 March 1. 